A major purpose or tne I ecrnncal Information Center is to provide the broadest dissemination possible of information contained in DOE's Research and Development Reports to business, industry, the academic community, and federal, state and local governments.

Although a small portion of this report is not reproducible, it is being made available to expedite the availability of information on the research discussed herein. 
LA-UR- $-88-3793$

DE89 003484

TITLE: OFTICAL TRANSITION RADIATION MEASUREMENTS FOR THE LOS ALAMOS AND BOEING FREE-ELECTRON LASER EXPERIMENTS

AUThOR(S): A. H. Lumpkin, P-15

K. B. Feldman, AT-6

D. W. Feldman, and S. A. Apgar, and B. E. Carlsten, AT-7

R. B. Fiorito and D. W. Rule, NSWC, Silver Spring, Maryland

Submitted to: The Tenth International Free Electron Laser Conference, August 29 . September 2, 1988, Jerusalem, Israel 


\section{DISCLAIMER}

This report was prepared as an account of work sponerred by an egency u? the Unitod States Government. Neither the Unitad Slates Government nor any agency theroof, nor any of their employees, makes any warranty, cxpress or implied, or asoumes any legal liability or responaibility for the accuracy, completenes, or usefuines of any information, upparatus, product, or procees dieclowed, or represents that its une would not infringe privately owned rights. Refer. ence herein to any specific commercial product, process, 0 . ecrvice by trade name, Irademark. munufacturer, of otherwise dose not neceses rily constitute or imply its endorsement, rocommendation, or favoring by the Uniled Sistes Ciovernment or any agency theroof The viow und opinsone of authors expreased herein do not neceasurily alate or reflect thine of the United Statea (iovernment or any agency thereof 


\title{
OPTICAL TRANSITION RADIATION MEASUREMENTS FOR THE LOS ALAMOS AND BOEING FREE-ELECTRON LASER EXPERIMENTS
}

\author{
A.H. Lumpkin, R. B. Feldman, D. W. Feldman, S. A. Apgar, and B. E. Carlsten \\ Los Alamos National Laboratjry \\ Los Alamos, New Mexico 87545, U.S.A. \\ and \\ R. B. Fiorito and D. W. Rule \\ Naval Surface Warfare Cente: \\ Silver Spring, Maryland 20903-5000, U.S.A.
}

\begin{abstract}
Optical transition radiation (OTR) measurements of the electron-beam emittance have been performed at a location just before the wiggler in the Los Alamos Free-Electron Laser (FEL) experinent. Beam profiles and beam divergence patterns from a single macropulse were recorcied simultaneously using two intensified charge-injection device (CID) television cameras and an optical beamsplitter. Both single-foil OTR and two-foil OTR interference experiments were performed. Preliminary results are compared to a reference variable quadrupole, single screen rechnique. New aspects of using OTR properties for pointing the e-beam on the FEL oscillator axis, as well as measuring e-beam emittance are addressed.
\end{abstract}

\section{IN'TRODUITION}

Characterization of the electron beam diiving a Free-Electron Laser (FEL) is an important aspect of optimizing such systems. In particular, good electron beam emittance can be a critical issue cnsuring spatial overlap of the optical and electron beams in the wiggler. An effective, newly developed technique for measuring electron-beam emittance on a single macropulse tand perhalps a few micropulses) of the high-current, high-energy electron beams uses the unifue pregesties of optical transition radiation (()TR). This radiation is emilted when a charged particle beam transits an interface between two media of different dielectric constants. Radiation is enitted in both forward and backward directions. The backward lobe is a functi $n$ of the Firesnel reflection coefficients so that detection at $90^{\circ}$ to the beam direction is practical |1-31. Preliminary beam-profile measurements at the Los Alanios Fti, were reposted

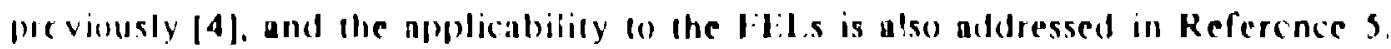


Two sets of measurements were successfully performed at Los Alamos. Beam profiles and beam-divergence patterns from a single screen were recorded using two intensified charge-injection device (CID) television cameras and an optical beamsplitter. Data were recorded with and without polarization effects on both $x$ and $y$ axes. The separation and width of the OTR angular distribution lobes $(\theta-1 / \gamma)$ agreed with the measured electron-beam energy. Preliminary analysis of the data yielded results consistent with the expected divergence of a few mrad. The beam-spot detector was also used in conjunction with the standard technique of varying the fields in a quadrupole doublet and measuring the spatial profiles. These data will allow a comparison of the OTR single-shot technique to the multishot quad-scan results. A twofoil OTR interference experiment was also performed. The comparison of these various emittance measurements will be discussed. Based on these results and further calculations, an OTR experiment for the Boeing FEL is being planned.

\section{TRANSITION RADIATION EXPERIMENTAL PROCEDURES}

As mentioned briefly in the introduction, OTR's unique properties can be exploited to provide minimally intercepting (thin foil or film) electron-bearn diagnostics for position and profile, intensity, emittance, and energy on a single macrcpulse. Figure I shows the qualitative OTR patterns for normal and oblique incidence as compared to Cherenkov radiation. When the OTR foil is at $45^{\circ}$ to the beam; the radiation is emitted in an annular pattern around a ray at $90^{\circ}$ to the beam direction, a standard viewing port geometry. In Fig. 2 the angular distribution pattern is displayed in more detail, and the lobe features include an opening angle $\theta_{p}$ proportional to $1 / \gamma$, a peak intensity proportional to $\gamma^{2}$, a lobe-width proportional to e-beam divergence (emittance), and a spectral function propurtional to $1 / \lambda^{2}$ for an aluminium foil for example.

The experiment was fieided at a position just before the wiggler in the Los Alamos FEL experiment as shown in Fig. 3. A $60^{\circ}$ achromatic bend brings the $20 \mathrm{MeV}$ e-beam onto the oscillator axis. Viewing ports on either side of the quadrupole doutlet (Q3) before the wiggler and screens at either end of the wiggler were used 10 align the beam with the laser reference on the oscillator axis. It is noted that for FELs an alignment laser often exists for this purpose. In this case. the same alignment laser is specularly reflected from the OTR foil and used to align the two intensified (ID) televisit,n cameras. A large diameter pellicle splits the CTR. Retroflections of the aligninent laser off tre camera sensors, intensifier entrance window, and the front surface of the two Nikon $85 \mathrm{~mm}, \mathrm{f} / 1.4$ lenses were used to align the detectors to about I mrad accuracy. A special object at infinity suurce was used to focus the angulat distribution camera [2], while fiducials at the OTR foil object plane were used to focus the 
other camera. The sensors were adjusted so that the laser spot was detected in the central channel ( $x$ and $y$ ) position of the data-acquisition system. A remotely iperated shutter and linear polarizer were placed at the exit port for the OTR source.

Figure 4 schematically shows how both the spatial intensity (beam spot profile) and the OTR angular distribution pattern can be recorded by focussing at the image plane and the focal plane (infinity), respectively. The spatial calibration was based on known fiducials in the object plane while the angular sensitivity was determined by deflecting a small laser heam with a motor-driven mirror and recording the mirror angle change and the pixel position of the spot in the microconputers.

We nominally operaied with about a 30- $\mu \mathrm{s}$-long macrcpulse, 46-ns micropulse spacing, and $\sim 1.2 \mathrm{nC} /$ micropulse, and minimal magnetic bunching in the $60^{\circ}$ bend. This implies the micropulse duration was about 25 ps and our peak currents were about $50 \mathrm{~A}$ and average currents were about $0.7 \mu \mathrm{A}$. Towards the end of the runs, we lengthened the rnacropulst to $100 \mu \mathrm{s}$, increased the charge to $3 \mathrm{nC} /$ micropulse, and bunched to our limit of about $10 \mathrm{ps}$. In this mude, the peak-current was $\sim 300 \mathrm{~A}$ and the average was $6 \mu \mathrm{A}$. The OTR foils were polished molybdenum, aluminized rused silica, and $7.6 \mu \mathrm{m}$-lhick Kapton.

\section{EXPERIMENTAL RESULTS AND PRELIMIIVARY CAL.CUI.ATIONS}

Data were obtained with both single-foil and two-foil setups and with several different e-beam focusing conditions and average curr 'nts. Due to space limitations only a few examples will be shown. It is highly probable that our simple assumptions on the electron-beam distributions will have to be modified to account for a core of good quality beam (lower emittance) superimposed with a halo of poor-quality beam (high emittance). Also, the present calculation does not include energy spread effects.

Fir. Jre 5 is a composite figure showing single-foil G, TR data for both beam divergence and beam profiles. The beam was focussed to an $x$-waist and the linear polarizer was ciriented horizonsally. The images are shown in the upper two quadrants and the profiles are displayed

in the two lower quadrants. In the lower left quadtant, the characteristic lobe-structure of $I_{\|}$is seen on the horizontal axis and $I$; for a vertical scan is shown on the vertical axis. The $x$ and $y$-beamspot profiles are seen in the lower right quadrant. ligure 6 shows a compatianll of the data in Fig. 5 to a calculation for $\mathrm{l}:-20 \mathrm{MeV}$ and the rms $x$-component of beam divergence of 4.9 mrad obtained from a least-squares fitting routine. The two lobe lleahs can be seen at approximately $125 \mathrm{mond}$ as expected for $y-41$. There are some deviations betuecen the ewo curves, and as mentioned in the opening of this section, this is a preliminaty anatysis. 
The $x$-component of emittance, $c x$, calculated by using the above value of $4.9 \mathrm{mrad}$ and the half width, half maximum intensity of the beamspot of $0.8 \mathrm{~mm}$ is $\epsilon=4 \pi \mathrm{mm}$ mrad. Similar values were obtained for the $y$-component of emittance, $\epsilon y$.

For comparison to the OTR angular pattern result, we used the variation of the beam spot profile with quadrupole (Q3) field variation to determine emittance somewhat independently (but using OTR light for the profile determinations). Using the fuli-width-at-half-maximum (FWHM) spot-diameter values, we fit the data to the appropriate hyperbola. We obtained unnormalized emittances of $\epsilon_{\lambda}=1.5 \pi \mathrm{mm} \mathrm{mrad}$ and $\epsilon_{y}=1.1 \mathrm{~mm} \mathrm{mrad}$, where it is noted that in these cases the $x$ and $y$ waists were obtained separately. We did not observe such small values when we tried to focus simultaneously in $x$ and $y$, nor when we ran at the higher peak current mode described in section II. The underlying assumption of the quadrupole focusing method is a uniform density ellipse in phase space, while the analysis of the OTR angular distribution was based on a gaussian distribution of beam-particle angles at the beam waist. Reconciliation of these two distributions should account for most of the differences between the two measurements [6]. Finally, the actual beam distributions may need to be modeled more carefully for both emittance measurement tecinniques. Energy-spread effects should be included in that step.

A two-foil OTR interference experiment was also performed. The first foil was a thin, transparent (7.6 $\mu \mathrm{m}=0.3 \mathrm{mil}) \mathrm{K}$ apton film spaced $0.5 \mathrm{~mm}$ in fron' of the aluminized fusedsilica screen. Figure 7 shows the predicted patterns for the paralles $\left(l_{\|}\right)$and nerpendicular $\left(I_{\perp}\right)$ polarization components for this system at $45^{\circ}$ to the beam and $l$ tivergences of 5.0 and 1.37 mrads. The latter value is an estimated lower limit for this assembly due to the beam scattering by the first foil. The predicted three fringes were observed with no filter, a $600-\mathrm{nm}$ band pass filter, and with the polarizer oriented on both $x$ and $y$ axis. Figure 8 shows $a$ horizontal profile through the experimental interference pattern with a $600 \times 40 \mathrm{~nm}$ bandpass liller. Several files of Jata are still to be analyaed.

In regard to foil survivability issues, we have some preliminary results also. The aluminized fused-silica screen was bombarded for several hours a day for four days at the lower current mode (still about 600 micropulsas per macropulse) with no observabie damage. However, at the high mole (2000 micropulses. $300 \mathrm{~A}$ peak current), the aluminum flaked off in tens of minutes. This may have been partially a differential heating effect with the fusedsilica substrate (which appeared undamaged). In the (wo-foil assembly, a similar experiment was betformed. We observed no apparent damage to the Kapton front foil, and the aluminized fused siliea was affected iess than in its single foil tests over tens of minutes. Kapton foil 
flatness or tautness may have altered curing the low- to higher-current runs, but no significant effect on the interference patterı, was observed.

As was noted in early OTR experiments by Wartski [7], the position of the central minimum of the OTR pattern is sensitive to the angle of interception of the electron bearn with respect to the foil normal. Thus by adjusting the steering magnets and observing both the beam image and the angular distribution image with respect to the laser reference points, one can carefully align the e-beam with the alignment laser axis, which in our case was also the FEL oscillator axis. This technique was used in our experiments, and should considerably simplify FEL e-beam tuning for the wiggler region.

Finally, we briefly address our preliminary designs for the Boeing FEL experiment. Since the e-beam energy is $110 \mathrm{MeV}$, larger spacing between the interferometer foils is possible . Therefore, we will be able to look at the front face of the second foil directly. Predicted interferograms for several cases of beam divergence are shown in Fig. 9. The upper figure shows the 0.4 and $0.6 \mathrm{mrad}$ for a foil spacing of $4 \mathrm{~cm}$, and the lower figure shows the difference between 0.6 and $0.9 \mathrm{mrad}$ for the foil spacing of $2 \mathrm{~cm}$. In both cases, a bandpass filter at $450 \mathrm{~nm}$ was assumed. Our initial experiments may use thin carbon foils as the first foil and existing polished-aluminum mirrors as the second surface. Our e-beam "pointing" studies will also be done during these experiments.

\section{SUMMARY AND CONCLUSIONS}

The OTR technique compares favorably with standard emittance diagnostics that rely on measurement sequences (quadrupole field variation) at one screen position or two screens. Several advantages for OTR are:

- Measurements are possible on a single macropulse (source strength permitting),

- Data structure and theory allow on-line evaluation of emiltance,

- A single position in the beamline can be used for e-beam profile, divergence, and angle (pointing) measurements,

- Thinner screens (foils) reduce beam scattering and $x$-ray production, and

- OTR provides a simultaneous e-beam energy diagnostic ( $1 \%$ alccuracy).

Some disadvantages are related to source brightness, the required careful optical alignments, and convolution of divergence and energy effects. In the final analysis though, 
OTR-based diagnostics should previde information vital to optimization of FEL performance and the validations of simulations of FEL experiments.

\section{REFERENCES}

1. L. Warski, et. al., J. Applied Phys. 46, 19753644.

2. R. B. Fiorito, et. al., Proc. 6th International Conference on High-Power Beams, Kobe, Japan, 1986.

3. D. W. Rule, "Transition Radiation Diagnostics for Intense Charged Particle Beams," Nucl. Inst. and Meth., B24/25, 1987 (901-904).

4. Alex H. Lumpkin, "Cherenkov and Transition Radiation Diagnostics for High-Energy Free-Electron Lasers," Fresented at AIAA 19th Fluid Dynamics, Plasma Dynamics and Lasers Conference, June 3-10, 1987, Honolulu, Hawaii, AIAA 87-1358, LA-UR-87-1535.

5. X. K. Maruyama, R. B. Fiorito, and D. W. Rule, "Oprical Transition Radiation as a Realtime, On-line Diagnostic for Free-Electron Laser Systems," Proceedings of the Ninth Internaıonal FEL Conference, Williamsburg, Va., September 1987, Nucl. Instr. and Meth., A272, 237, October 1988.

6. Claude LeJeune and Jean Aubert, "Emittance and Brightness: Definitions and Measurements," Adv. in Electronics and Electron Physics, Suppl. 13A, 158-259, 1980.

7. L. Wartski, "Study on Optical Transition Radiation Produced by 30 to $70 \mathrm{MeV}$ Energy Electrons. Application to the diagnosis of beams of charged particles," Ph.D. Thesis, Université de Paris - Sud, Centre d’ Orsay, 1976 (unpublished). 
Figure Captions

Fig. 1. A schematic representation of OTR and Cherenkov radiation patterns.

Fig. 2. A schematic representation of the OTR angular distribution pattern dependence on e-beam parameters where $\boldsymbol{\gamma}$ is the Lorentz factor..

Fig. 3. A schematic experimental setup for the OTR experiments on the Los Alamos FEL.

Fig. 4. A schematic representation of the focus at the object (beam spot) and focus at infinity (angular distribution) techniques.

Fig. 5. A composite of OTR single foil data showing both divergence and beam spot images (upper) and profiles (lower).

Fig. 6. A comparison of divergence data from Fig. 5 to a calculation with $\sigma=4.9 \mathrm{mrad}$.

Fig. 7. Predicted interferogram patterns for the Los Alamos case.

Fig. 8. Experimental profile for the interference experiment data exhibiting the expected three fringes.

Fig. 9. Predicted interferogram for several cases of e-beam divergence for the Boeinz FEL case. 


\section{OPTICAL TRANSITION RADIATION PATTERNS}

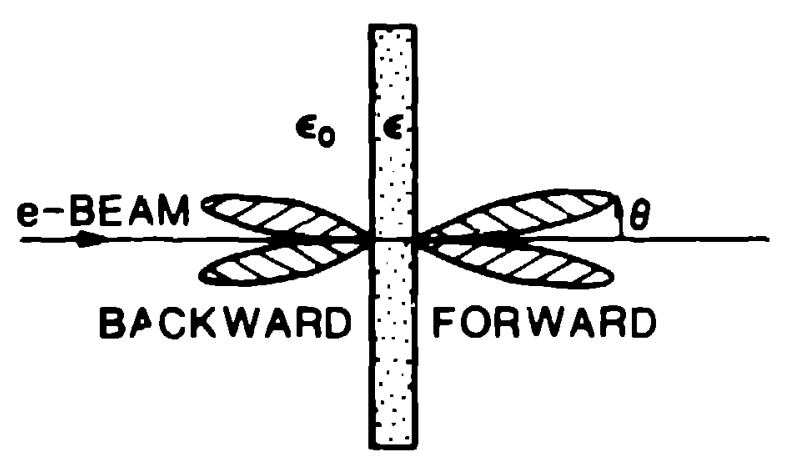

a.) NORMAL INCIDENCE

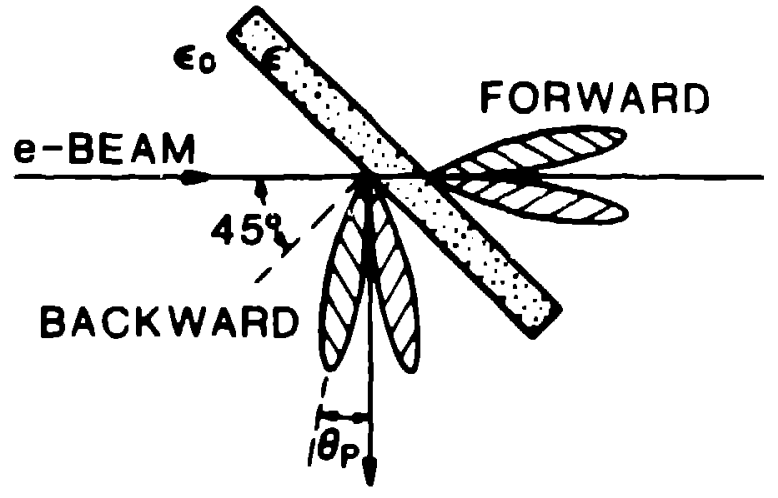

b.) OBLIQUE INCIDENCE $\left(\phi=45^{\circ}\right)$

CHERENKOV RADIATION PATTERN $\left(\theta \sim 46^{\circ}\right)$

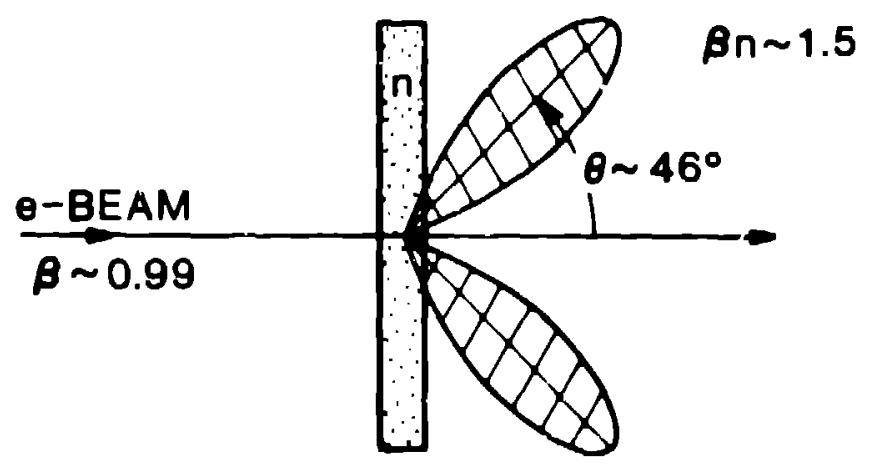

FIg. 1 


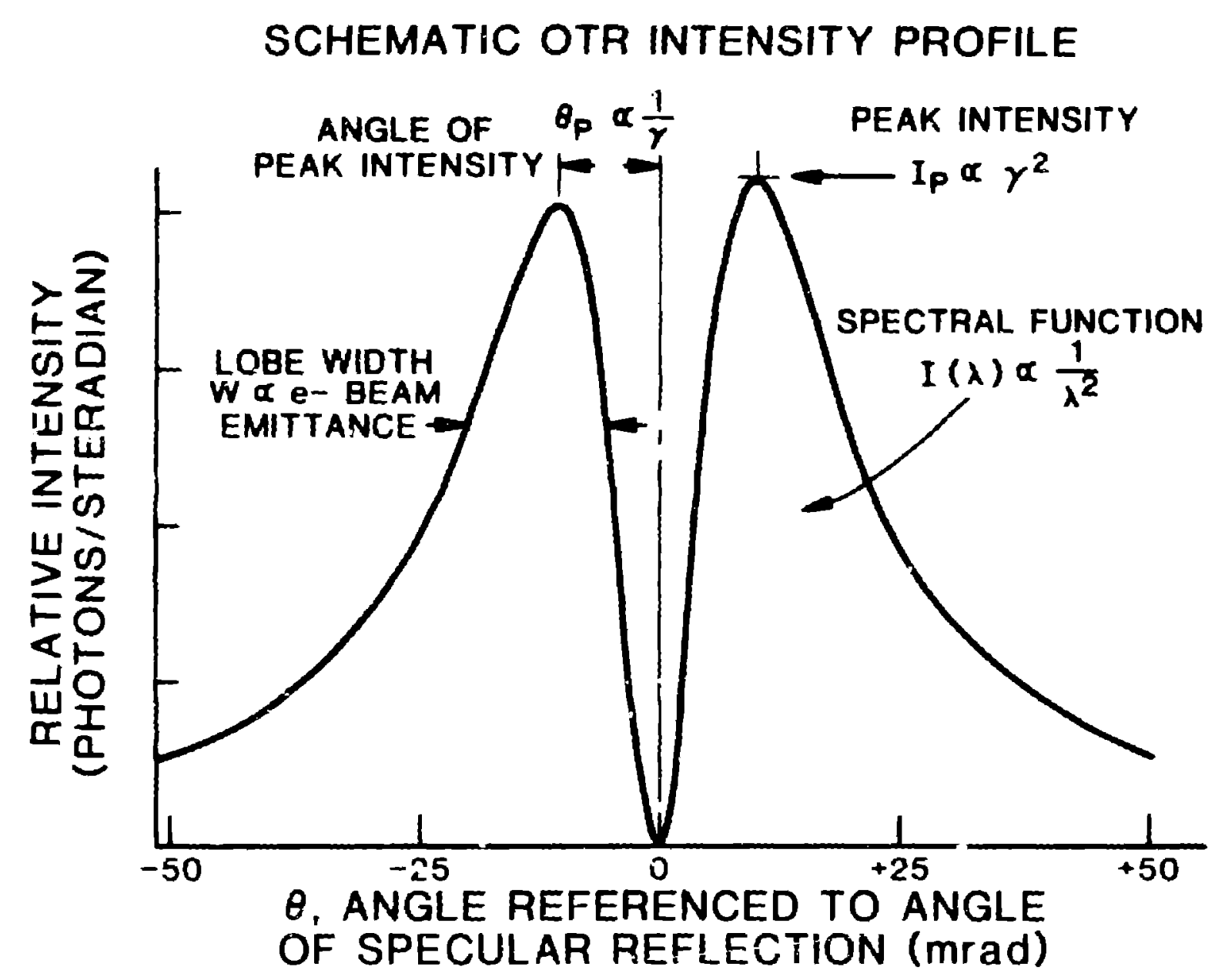




\section{Schematic of OTR Experiment ( Los Alamos )}

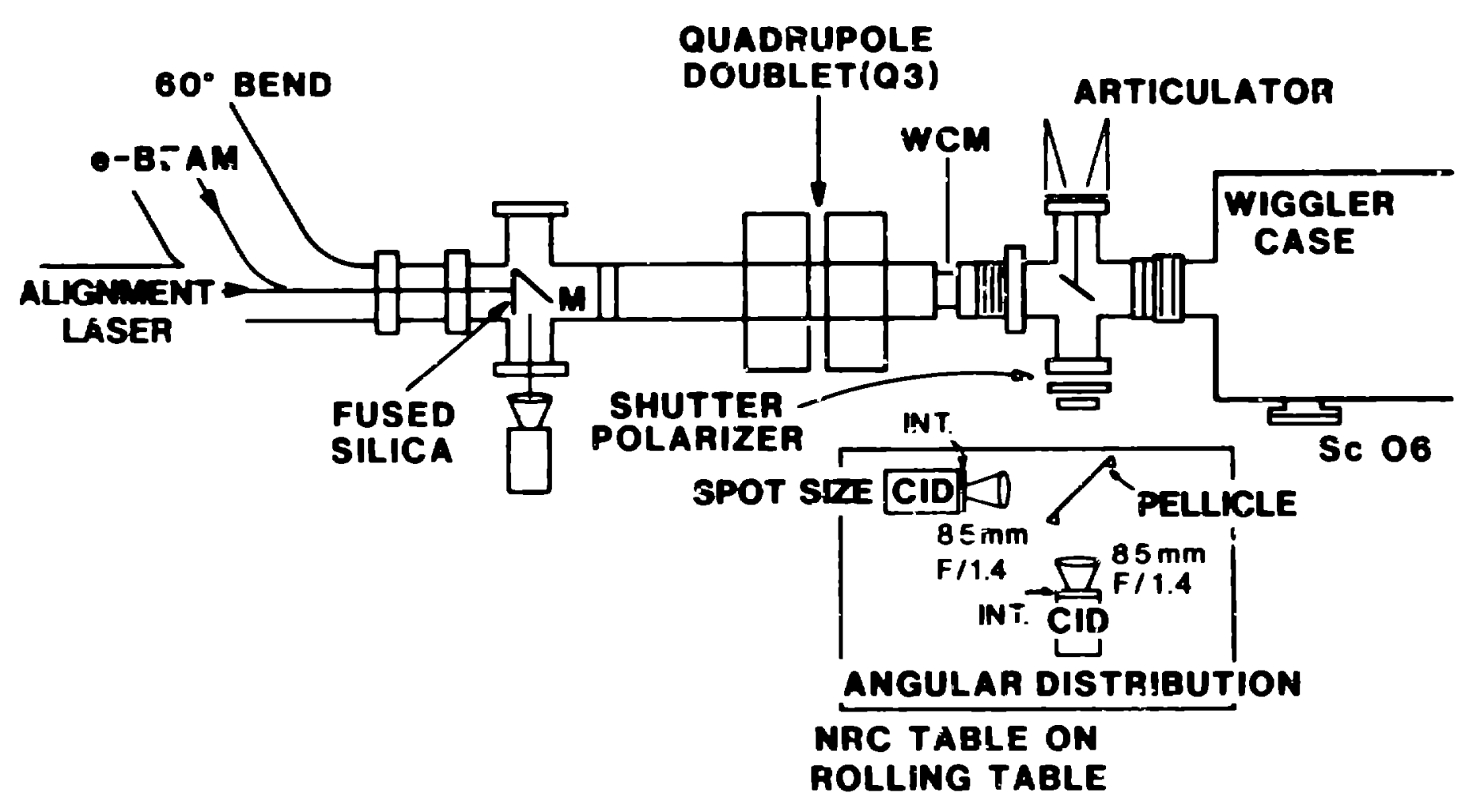




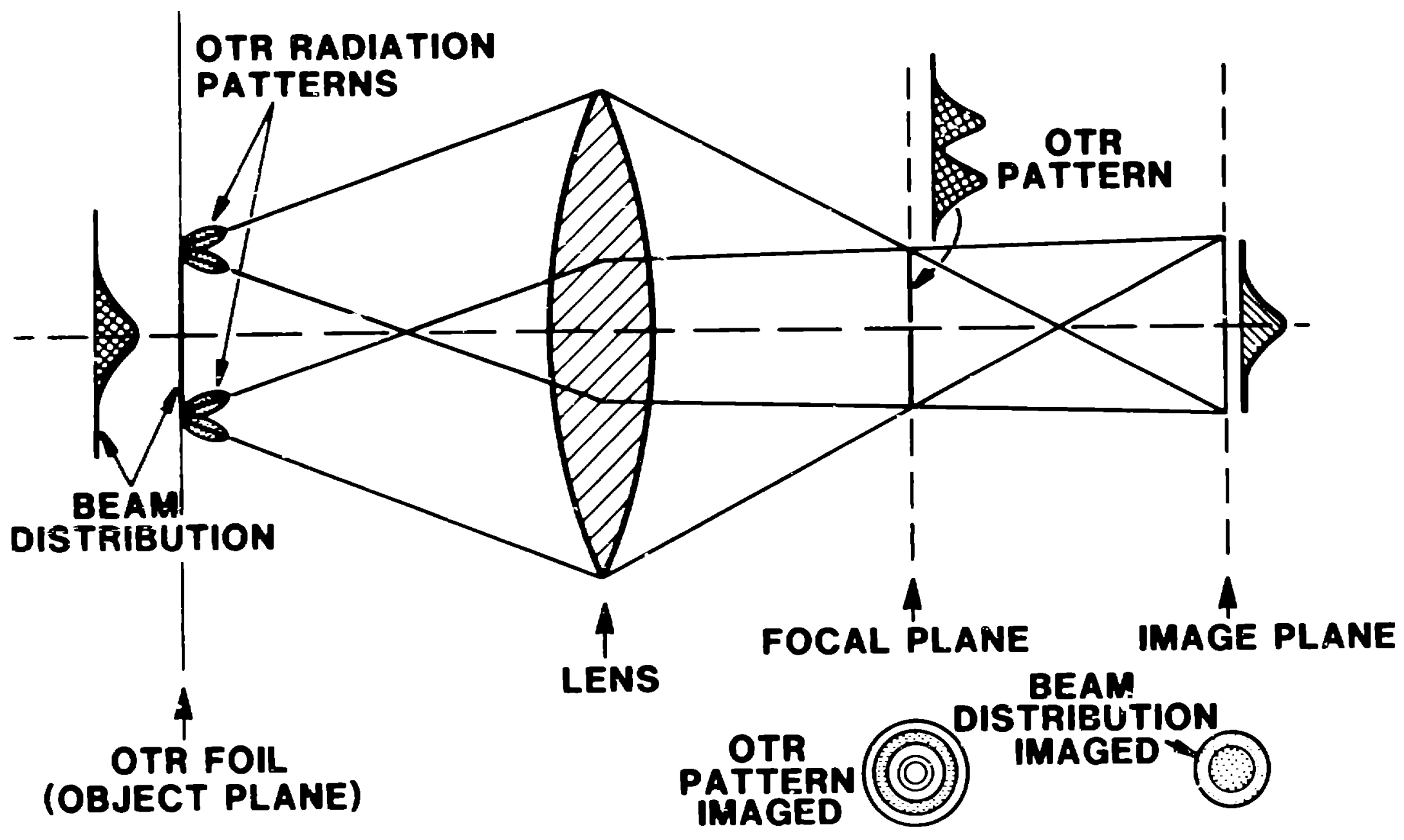




\section{Single Foil OrR Data}

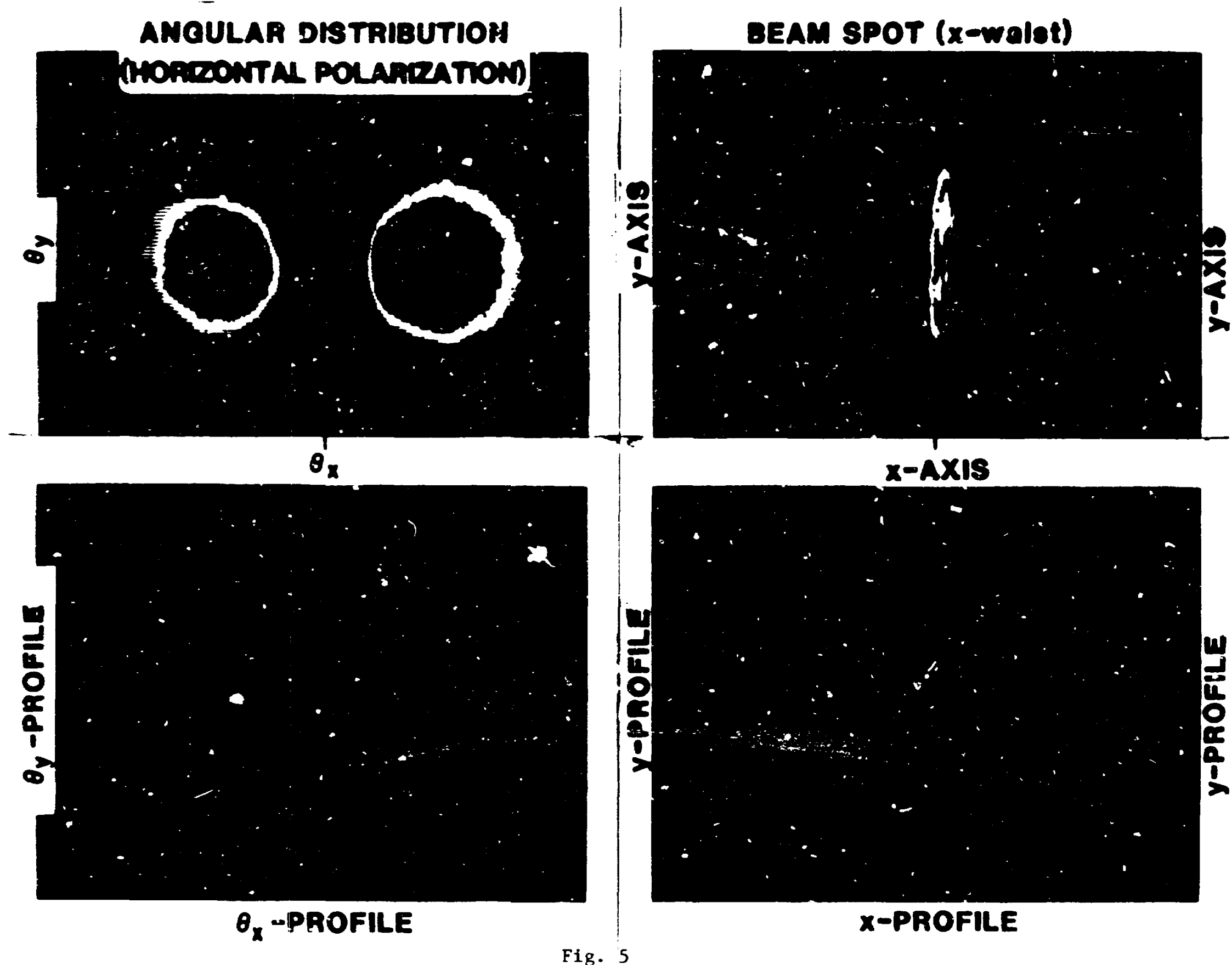


SINGLE FOIL DIVERGENCE RESULTS $20 \mathrm{MeV}, 4.8 \mathrm{mrad}, x$-walst

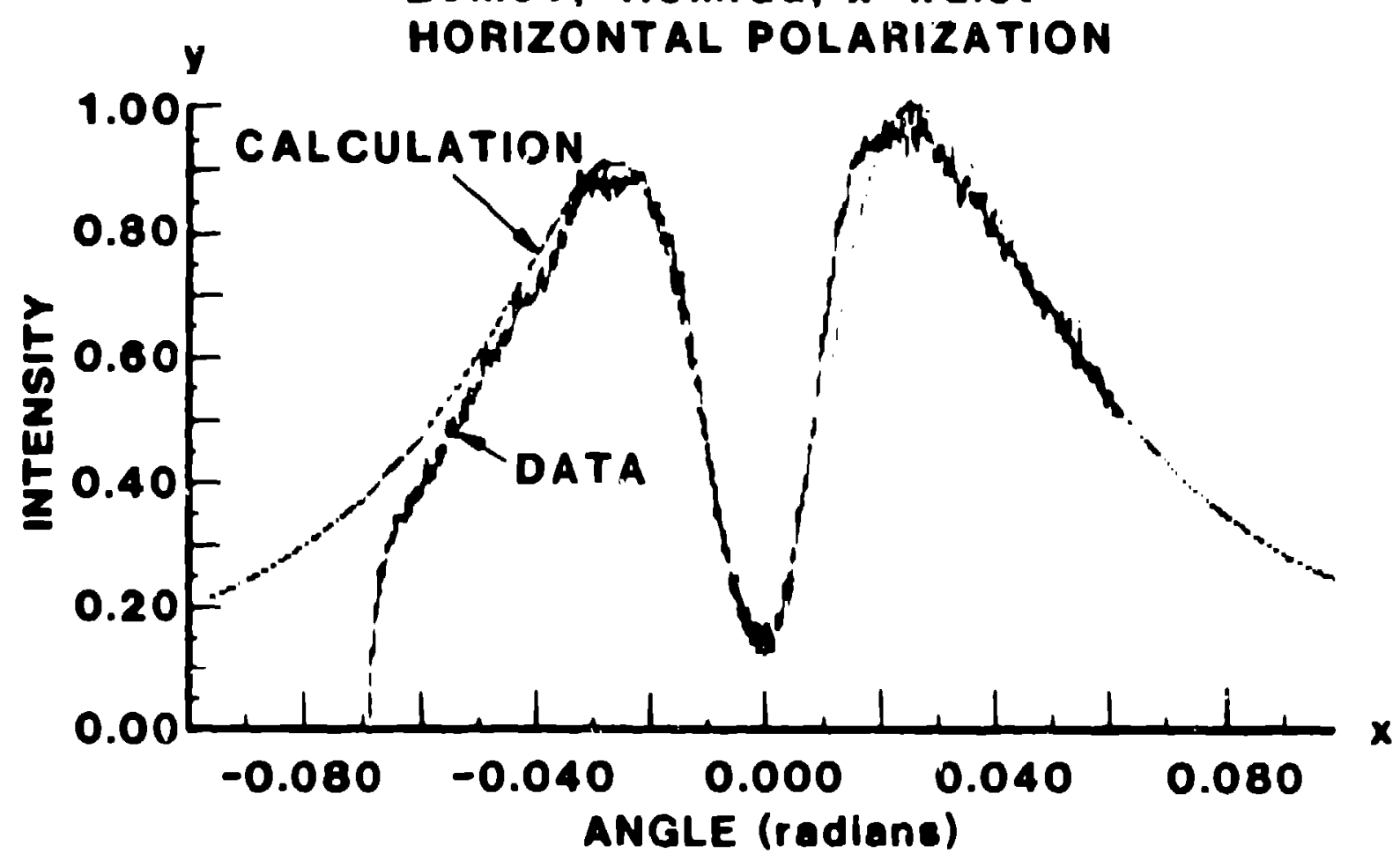

114. 6 
$-14-$

$E_{B}=20 \mathrm{M} \bullet \mathrm{V}$

INTERFEROGRAM

(CALCULATED)
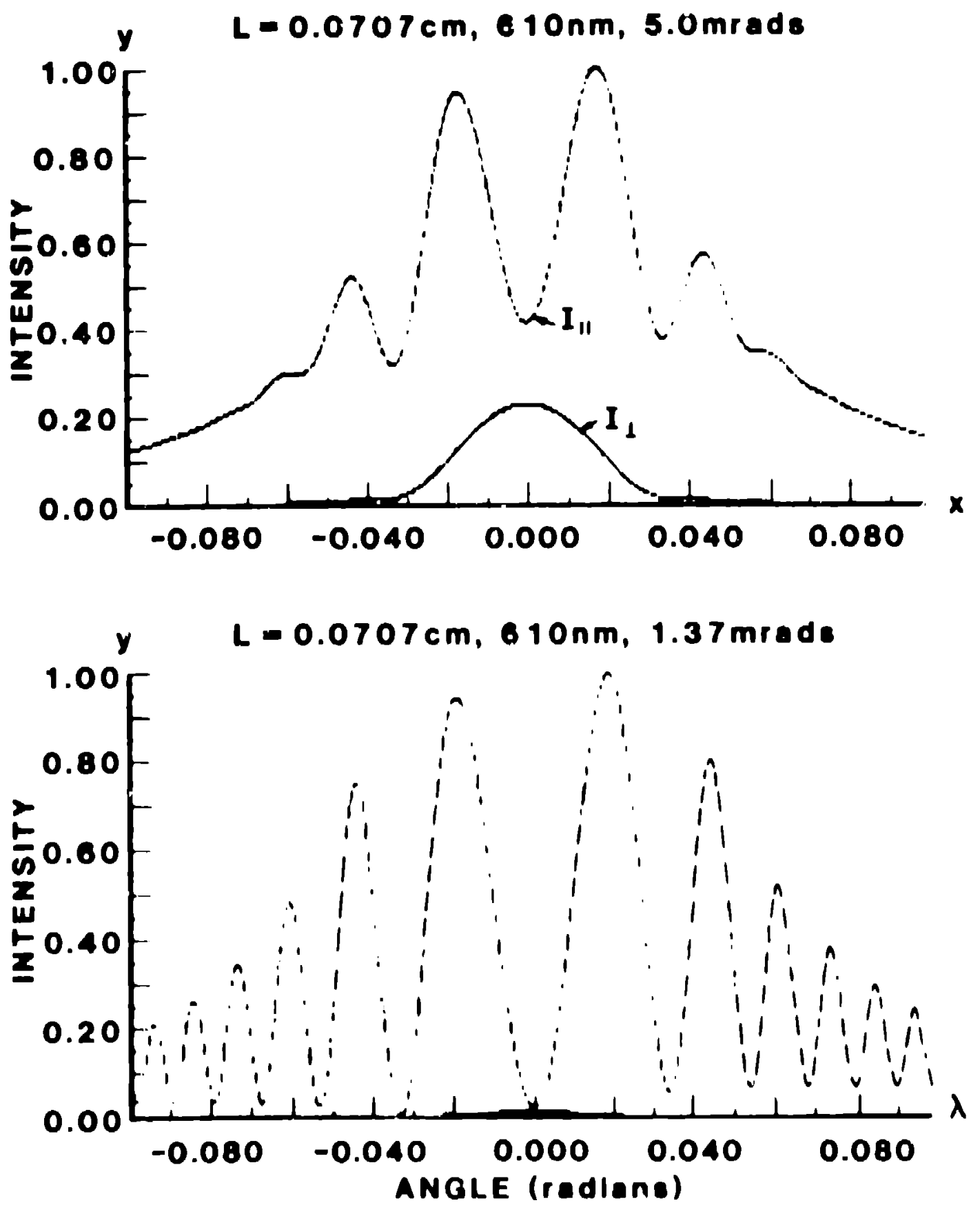

Hi. I 


\section{Initial Two-Foil Interference Pattern}

FOCUS: $x, y$ WAIST

FILTER: $600 \times 40 \mathrm{~nm}$

POLAR.: HORIZONTAL

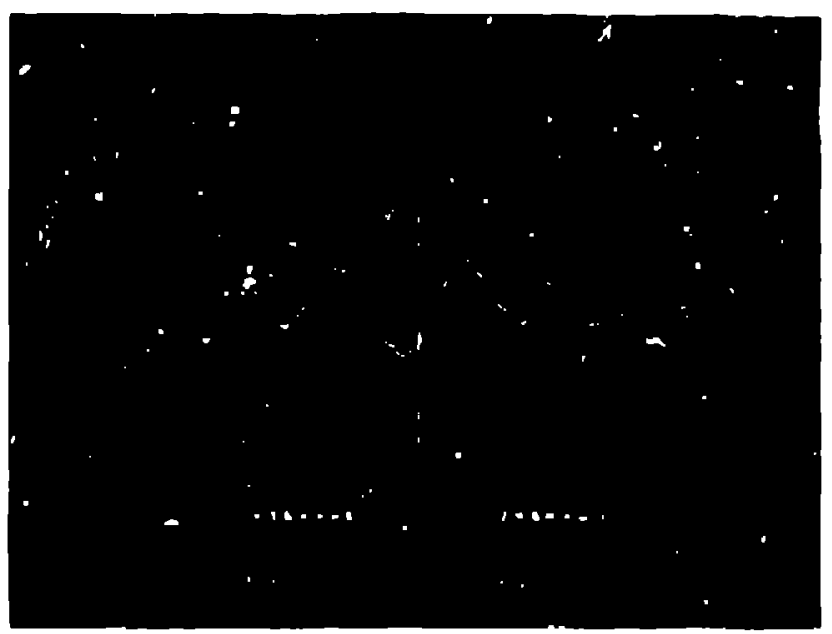

FIRST FOIL: KAPTON

SECOND FOIL: ALUMINIZED FUSED SILICA

SEPARATION: $0.5 \mathrm{~mm}$ NORMAL

$0.7 \mathrm{~mm}$ (O $45^{\circ}$ 
INITIAL PREDICTED INTERFEROGRAM FOR BOEING BURST MODE ELECTRON-BEAM EMITTANCE 1 10MEV, BEAM DIV. $0.420 .6 \mathrm{mrad,} 450 \mathrm{~nm}, \mathrm{~L}=4 \mathrm{~cm}$

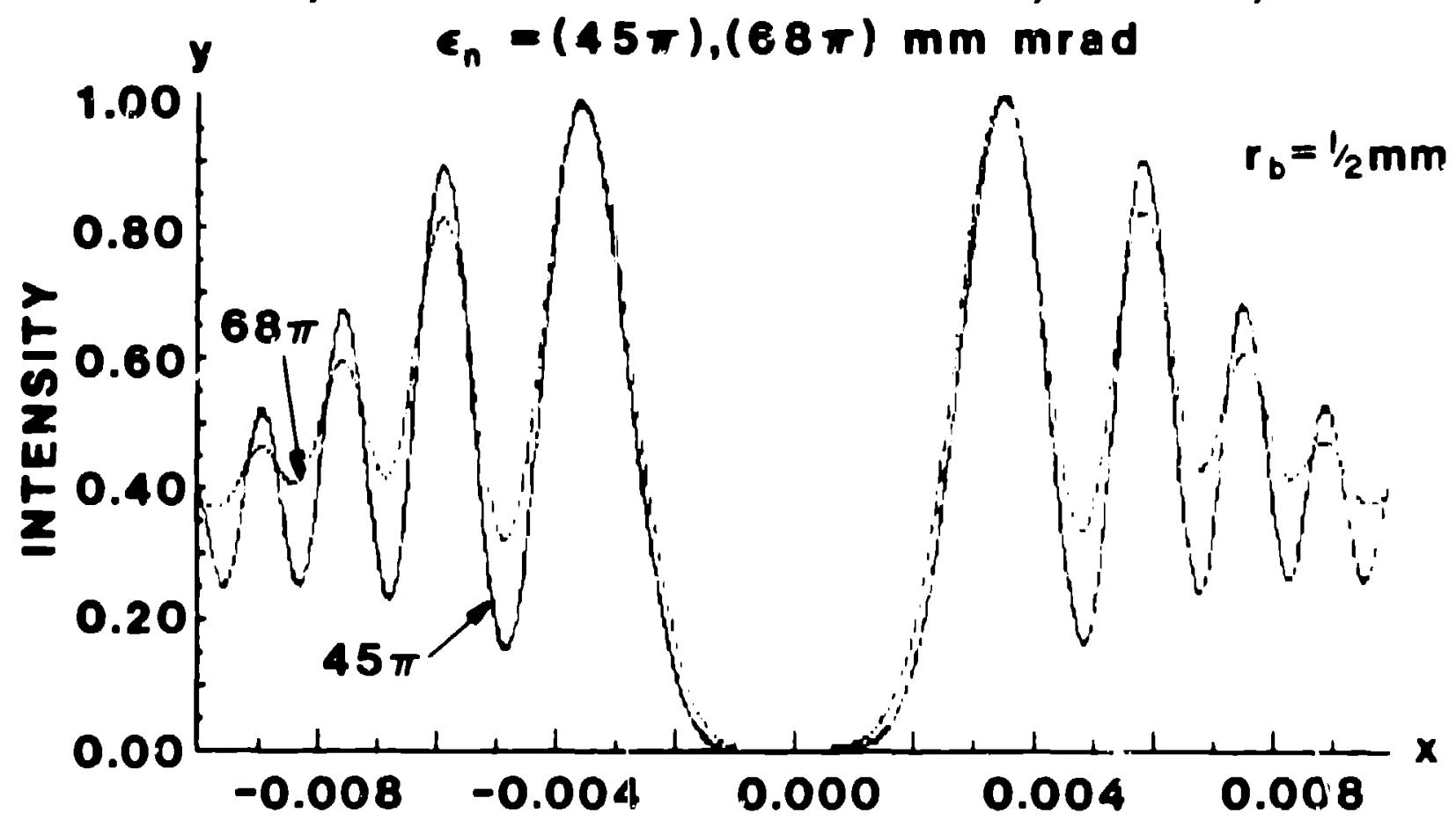

$110 \mathrm{M} \odot V$, BEAM DIV. $0.6 \& 0.9,450 \mathrm{~nm}, L=2 \mathrm{cIn}$

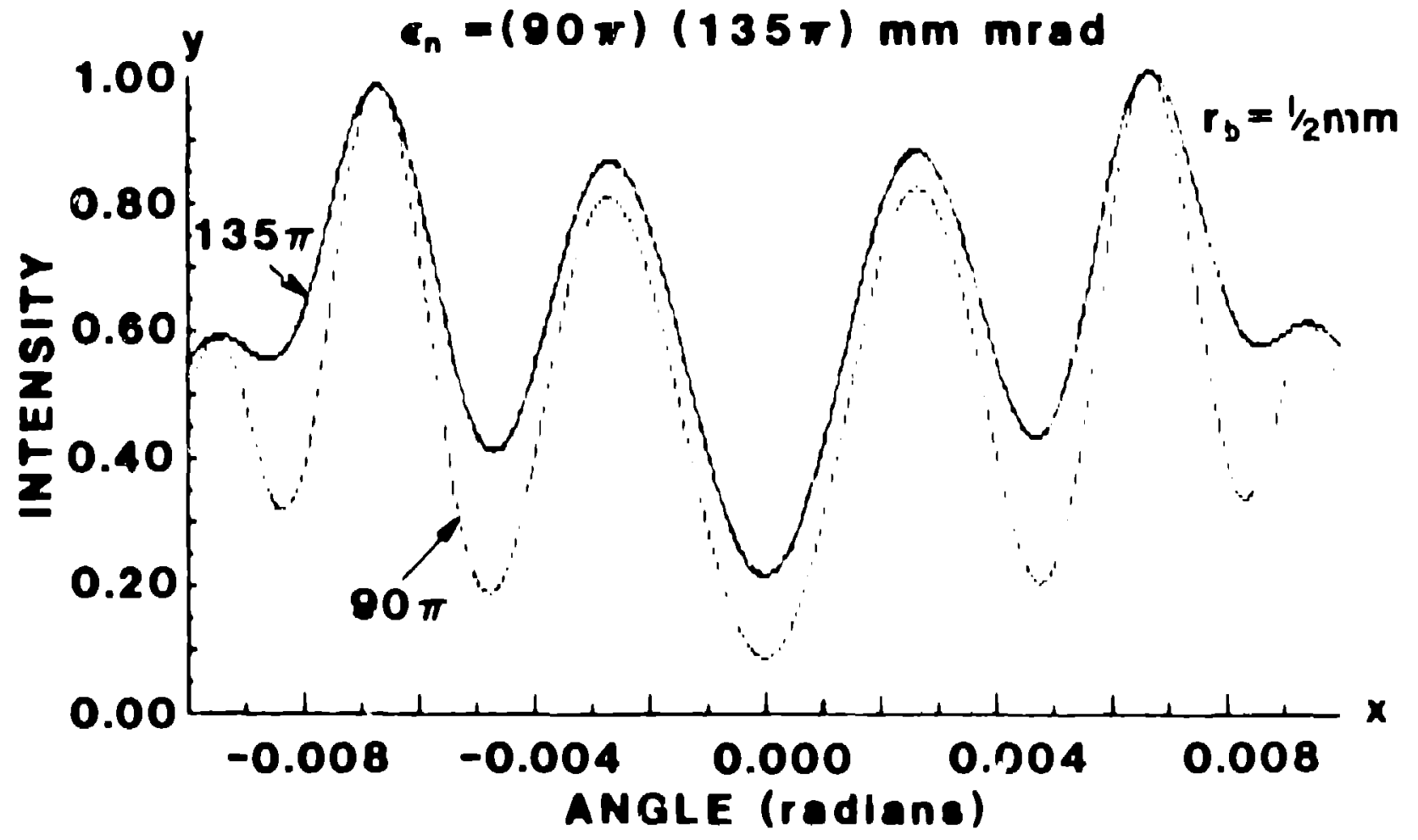

